\title{
RELATIONSHIP BREAKUPS
}

\author{
Collin Jerome \\ Centre for Language Studies, Universiti Malaysia Sarawak \\ jcollin@cls.unimas.my
}

\begin{abstract}
Breaking up a relationship is not easy. Those on the verge of breaking up with their spouses may use different verbal and non-verbal means to express their desire to end the relationship. The following poems attempt to tell the complex processes of, and the mediums used for, relationship breakups.
\end{abstract}

Keywords: relationships, poems, breakups.

\section{Distant}

Why does it have to be complicated

The sun

$$
\text { The moon }
$$

The hills

The trees

Distant yet

Close to our hearts

The grass bends

As the wind blows

The crickets sing

In euphoria

Fireflies loom

In the sky

But why does it

Have to be like this

End like this

When what I ask is only for you to

listen

\section{Remind Me}

Don't remind me

Of the things

Said and done

For there is nothing

You or me to

Say or do

To mend us

Don't remind me

Of the questions

Asked and answered

For your question

Need no answer

For I know

And you too

Remind me

Of the bills

And debts

Time wasted

Money spent

Feelings deceived

There are more on the list

Remind me

Of the little names

You used to call me

Words you used to say

Faces that you used to make

When we used to be

What it used to be

Don't remind me 
Type

Send

'I wanna break up'

Type

send

'I dun luv u anymore'

Type

send

Are we cowards?

This is better

Less bruises

Less talk

\section{Chinese Brush}

It's not a smooth line that this brush produces

A line that shivers

as it moves with the trembling force

of the delicate fingers that once touched my back

A line that baffles Sung and Chou and puzzles both $\mathrm{Li} P O$ and $\mathrm{Tu} F u$

But it's a line that manifests our visions and dreams

a line that prophesizes our unbreakable bond

As you lift your hand, the line ends Your calligrapher's block persists.

But it's not you; It's Us

Us on a dead end

If you leave,

I shall yearn the

lingering faint-smell of

your ivory-yellowed skin.

Those squinted eyes you inherited from your tiny-feet ancestor

But go if you insist.

Take your brush

and never knock on

my Door again. 